\title{
Green Construction: Status and Prospects of Shenzhen Construction Industry's “Double Carbon” Goal
}

\author{
Hongzhou Chen* \\ The Chinese University of Hong Kong (Shenzhen), Shenzhen 518172, Guangdong Province, China \\ *Corresponding author: Hongzhou Chen, hongzhouchen1@link.cuhk.edu.cn
}

\begin{abstract}
Shenzhen has extensive green construction experience as one of China's new green development pilot cities. Shenzhen has experienced substantial economic growth as a result of the reform and opening up, but it has also had to face the burden of urbanization problems and difficulties. This article looks at the history of green construction in Shenzhen and how the spirit of the city influenced it. The work then divides the procedure into two phases and examines the issues that arise. Suggestions for achieving the "Double Carbon" aim in the building industry are sought through this effort.
\end{abstract}

Keywords: Double Carbon goal; Green construction; Urbanization; Sustainable development; Shenzhen

Publication date: November 2021; Online publication: November 30, 2021

\section{Introduction}

2021 is the first anniversary of China's official "Double Carbon" goal (by 2030, China's carbon emission will arrive at its peak and, by 2060, will achieve its carbon neutrality). During this year, the government, enterprises, and scholars have conducted a lot of research and work focusing on energy supply and use and have achieved significant and long-lasting results. It is true that, among the carbon emissions of various industries in China, the power and energy industry still account for about $40 \%$ of the total emissions of the society and is the primary project and critical player in achieving the "Double Carbon" target. Still, it is also crucial and urgent to implement the "Double Carbon" in the construction industry.

According to the International Energy Agency (IEA) ${ }^{[1]}$, the carbon emissions caused by the construction of buildings accounted for $10 \%$ of the total emissions of all industries. In comparison, the carbon emitted by facilities in use accounted for $28 \%$ of the global carbon emissions in 2019. In addition, the "Global Status Buildings 2020" report from the United Nations Environment Program (UNEP) shows that not only has the global construction industry barely reduced its total energy consumption in recent years, but its carbon emissions are setting new records consistently ${ }^{[2]}$. Globally, paying attention to the construction industry has become an integral part of achieving the "Double Carbon" goal.

Similarly, the situation in China's construction sector is not encouraging. According to studies, China's domestic construction industry may have to achieve its emission peak nine years later than the overall national "2030" target, making it the last of all significant production sectors in China to achieve the "Double Carbon" target ${ }^{[3]}$. With the global spreading concept of environmental protection and sustainable development in recent years, there is no doubt about the determination of China's Party and its government to achieve the "Double Carbon" target. This is an economic transformation and a revolutionary innovation from thought to practice to realize the concept of human destiny community and the great rejuvenation of the Chinese nation. Thus, the "Double Carbon" reform in China's construction industry is imminent. 
The Ministry of Housing and Urban-Rural Development (MoHURD) of China, in its "Letter on Green Construction Pilot Work" issued in January 2021, clearly proposed to designate Shenzhen as one of the three pilot regions (the other two being Hunan Province and Changzhou City) to carry out green construction pilot work. Subsequently, the MoHURD prepared and released the "Green Construction Technology Guidelines (for Trial Implementation)" in March and the interpretation of the Guidelines in April. These policies propose "effectively reduce the consumption of resources and the impact on the ecological environment during the whole construction process, reduce carbon emissions, and improve the overall greening of construction activities," and "integrate the concept of green development into the whole element and process of engineering construction, comprehensively enhance the green and low-carbon development of the construction industry, and promote the full implementation of the national "Double Carbon" major decisions in the construction industry ${ }^{[4]}$." This paper argues that compared with other green construction pilot sites, Shenzhen, as the first region in China to put forward "green and low-carbon construction" related decree documents and implementation, studying its prior experience and the problems it may face now has more potential to promote "green construction" in other regions and realize the "Double Carbon" goal in the whole construction industry.

\section{Facing "Unsustainable," the first to explore the search for a breakthrough}

As China's first special economic zone, Shenzhen has been the window and testing ground for China's reform and opening up. But this achievement also means that Shenzhen will bear the brunt of many problems and difficulties in the urbanization process and has no predecessor to learn from.

Since its establishment in 1979, Shenzhen's GDP had grown from 196 million yuan to 166.524 billion yuan in 2000, making it the fourth largest city in terms of GDP after Shanghai, Beijing, and Guangzhou, and shaping the pattern of China's first-tier cities ${ }^{[5]}$. However, along with the rapid development of Shenzhen, "land space," "energy and water resources," "labor force," and "ecosystem carrying capacity" ${ }^{[6]}$ had become a severe dilemma in front of Shenzhen. Shenzhen Urban Planning and Design Institute statistics, around 2000, Shenzhen has been building land area of 467.3 square kilometers, accounting for $60.73 \%$ of the total building land resources (767.75 square kilometers). This data means that Shenzhen has entered a highly constrained stage of urban development. Also due to the building process and consumption and pollution from the consequent use of environmental resources, Shenzhen is expected to go forward to the most deteriorating rigid constraint stage of its development in 2008.

To avoid such results, the Shenzhen government issued the local standard for building energy efficiency in 2003. This design code innovatively combines "saving social resources and achieving sustainable development" with building design and construction and marks the first step in Shenzhen's quest for a breakthrough in the face of the dilemma of natural resources and the ecological environment ${ }^{[7-}$ ${ }^{8}$. Subsequently, after serious discussion and analysis, Shenzhen took the initiative to lower gross domestic product (GDP) expectations and placed the "ecological environment" on the same level as "economic development" in urban construction ${ }^{[9]}$.

At the same time, due to Shenzhen's market environment and the city's spirit of "pioneering and innovation," Fraser Place Shenzhen was designed and built by the U.S. Green Building Council (LEED) standards. Newsweek hailed it as "China's first green commercial building" ${ }^{[10]}$ in 2005. The following year, Shenzhen first issued the "Special Economic Zone Building Energy Efficiency Regulations," implementing the country's strictest building "one ballot veto" system ${ }^{[11]}$. This system requires $100 \%$ of new buildings to meet energy efficiency standards. By now, Shenzhen, as the first urban area in the country to face a severe economic and natural dilemma, has achieved a transformation from a nascent start to selfexploration and then full implementation of green and low-carbon transformation in the building industry. 


\section{Affirming the "spirit of Shenzhen," but period shortcomings are also imperative}

It is undeniable that Shenzhen has been positioned as a testing ground for various national policies since its inception, and thus enjoys more financial support and opportunities to showcase. However, by reviewing the process of green transformation of buildings and construction industry in Shenzhen, we can find that the "Shenzhen spirit" of "daring to break new ground, openness and tolerance, pragmatism and law, and the pursuit of excellence" has always been the main line of green construction in Shenzhen. It is an important foundation and guarantee for the accomplishment of today's results.

First of all, from 2003, Shenzhen began to incorporate environmental elements into urban construction. In the face of development problems, it is refusing to "sit back and wait" for instructions and help from the higher level, "dare to breakthrough." Shenzhen explored a suitable path for its development, which is ahead of the other regions. Secondly, in the face of the fact that green building technology was developed earlier abroad, Shenzhen actively introduces foreign capital and technology to establish strategic cooperation. It also promotes convergence and mutual recognition with international green building standards.

"Pragmatism and law" are reflected in the green building standards and documents promulgated by Shenzhen. Take the Shenzhen "Public Housing Construction Standard" promulgated in July this year as an example. Based on the foundation of previous work, the standard incorporates the central government's "green construction pilot" planning on "promoting BIM technology," relying on "5G, Internet of Things, blockchain and artificial intelligence," from 9 chapters and 128 items to clarify green construction's requirements. Converting macro instructions into standard documents ensures rules to follow, avoiding the fuzzy governance environment ${ }^{[12]}$. Finally, since Shenzhen has achieved remarkable results after the reform and opening up, it's often established as a benchmark in China's governmental programs. Shenzhen has often chosen to take advantage of opportunities due to its spirit of "pursuit of excellence."

While analyzing and learning from the experience of Shenzhen's efforts to promote green construction, it should also see its problems. This paper believes that introducing the subsidy of green building in Shenzhen in 2012 as the boundary can be divided into two stages for separate analysis. In Phase I (20032012), although some policy documents have been issued, the public, the market, and the executive departments were not sufficiently aware of the concept of environmental protection. Moreover, developers blindly believed that the initial investment in building energy-efficient buildings was too high and the investment risk was too significant. Additionally, the documentary standards in this phase were mainly thermal parameters, which lack practical guidance for the architectural design and construction process. Furthermore, for a long time, the government's long-standing "campaign-style" governance of non-GDP core projects has led to a "weakened prestige" and a "speculative mentality" in the market ${ }^{[13]}$. Hence, as of 2008, green projects had emerged in Shenzhen.

Phase II (2012-2020) is marked by the introduction of the Shenzhen Measures for the "Management of Special Funds for Building Energy Efficiency." The Measures specify subsidies for the construction and operation of green building projects, both up to RMB 6.5 million/item. As seen from government data, the Measures have ushered in a rapid development phase for green building. By the end of 2018, Shenzhen had more than 100 million square meters of green building area and a total of more than 1,000 projects. Taking the Qianhai District as an example, its government has made an ambitious plan for all buildings in the district to be green. Therefore, compared with 2012, the city's green construction area has expanded ten times.

However, the problems of phase II followed. Since 2018, Shenzhen has seen several enterprises give up green financial subsidies. In 2019, for example, the "abandonment rate" was $60 \%$. The reason is that green buildings often cost more to build and operate than traditional buildings to achieve low-carbon or even carbon-neutral purposes, so many enterprises view green buildings as a burden. In addition, there has been a lot of research on the drawbacks of the governance model of relying on subsidies to promote projects 
[14]. This development model not only breeds rent-seeking but also makes green buildings unsustainable. Finally, with the promotion of green building projects, how to solve the phenomenon that new buildings in new areas are "green," but old buildings in old districts are difficult to "reform" is also urgent for Shenzhen to think about.

\section{Relying on "city clusters," the financial empowerment promotes "Double Carbon" goal}

Combing China's green construction program can be seen; the work is not only aimed at three pilot regions but to explore a viable approach to the construction industry's "Double Carbon" goal. The central government encourages the pilot regions to integrate regional resources and actively expand the effect in this process. Combining the previous experience of Shenzhen, this work holds that the Shenzhen government should use "green finance" instead of "green subsidies" to play a market role and rely on "city clusters" of the Greater Bay Area to fulfill the "Double Carbon" goal.

Green finance mainly includes green credit, green bonds, carbon emission trading market, ESG investment, and green insurance. Among them, green credit is relatively mature, and also is the product with the earliest start and most comprehensive development in China. It is mainly invested in transportation and energy fields. Meanwhile, mortgage loans for green buildings in China are also gradually increasing. Green bonds are debt issued for the purpose of environmental projects. At present, the scale of global green bonds reaches nearly $\$ 300$ billion. After China releases its green bond standards this year, the domestic green bond market will enter a rapid growth stage. The carbon emissions trading market, also known as the carbon trading market, is a powerful tool to achieve the goal of "Double Carbon." ESG investment is an internationally famous investment system. Currently, most domestic ESG products in China are based on a vague concept, and there is still much room for growth. Green insurance is a popular international tool to reduce the risk of enterprises in achieving the goal of "Double Carbon." It is generally based on pollution mitigation liability insurance and is expanded to cover significant disaster insurance, green building insurance, and carbon insurance. At present, the innovation of green insurance in China is still in the exploration stage, and further development is needed.

The "Double Carbon" goal is challenging to achieve by the resources of a single city. Cement, for example, the primary raw material used in construction, is the most important source of carbon emissions in the building sector, accounting for $7 \%$ of global carbon emissions (in 2018). To solve this challenge, foreign research institutions and companies had developed carbon-negative cement that can absorb carbon dioxide and put it into use in 2014. However, take Tower Cement, one of the leading suppliers of cement for constructing China's Great Bay Area, as an example. The company's main environmental management objectives are still in the traditional areas of nitrogen reduction and denitrification. Therefore, to achieve the "Double Carbon," it is necessary for the government to take the lead and integrate resources in the whole region for a comprehensive plan. This requires Shenzhen's experience and the regional city cluster's gathering effect.

Undoubtedly, the emergence of the city cluster is the inevitable product of the development of productivity and the gradual optimization of production factors ${ }^{[15]}$. Specifically, to green construction and the construction industry's "Double Carbon" target on the ground, Shenzhen's preliminary work has accumulated experience in the sustainable development of the construction industry. The establishment of Qianhai and Hengqin special zones and the institutional innovation of the supporting financial reform program will promote the development of green finance and empower the construction industry to achieve the green goal. It can be seen that if each city in the Greater Bay Area can base on its own geographical and industrial characteristics and take positive actions to promote integration, it will provide a more optimal spatial layout of industrial land, front-end upgrading of industry-research docking, and carbon reduction effect of transportation after optimizing infrastructure for the whole region. It is foreseeable that the pilot 
work of "green construction" in Shenzhen and the Greater Bay Area will submit a satisfactory answer and valuable experience.

\section{Disclosure statement}

The author declares no conflict of interest.

\section{References}

[1] 2021, International Energy Agency, https://www.iea.org/data-and-statistics/databrowser/?country=WORLD\&fuel=CO2+emissions, www.iea.org/buildings

[2] United Nations, 2020, "Global Status Report for Buildings and Construction." Available at https://globalabc.org/sites/default/files/inlinefiles/2020\%20Buildings\%20GSR_FULL\%20REPORT.pdf

[3] Industrial and Financial Systems, 2021, "Towards Carbon Neutral 2060: Embracing New Opportunities for Low Carbon Development," https://www.sohu.com/a/456519184_120661187

[4] Ministry of Housing and Construction of the People's Republic of China, Letter on Green Construction Pilot Work, 2021, http://www.mohurd.gov.cn/wjfb/202103/t20210319_249507.html

[5] Interpreting the "Green Construction Technology Guidelines (Trial), 2021, http://www.mohurd.gov.cn/zxydt/202104/t20210415_249788.html

[6] 2001, China Statistical Yearbook, China Statistics Press, 20.

[7] Li HZ, 2005, Four "Unsustainable" into a Bottleneck, where is the Road for Shenzhen?, http://news.gd.sina.com.cn/local/2005-05-17/1309573.html

[8] Ma XW, et al., 2006, Energy-Saving Design Practices for Residential Buildings in Shenzhen. PhD diss.

[9] Shenzhen Housing and Construction Bureau, 2021, Green Building Column, http://zjj.sz.gov.cn/xxgk/ztzl/jzjn/

[10] Wu L, Zhao DH, 2004, Insights from Shenzhen's Delayed Modernization Schedule. Financial Information Reference, 6: 47-47.

[11] $\mathrm{Hu}$ JX, Lin WS, 2007, Green Building and Harmonious Home - Energy-Saving Design of China Merchants Tiger Apartments, Journal of Architecture, 4: 17-19.

[12] Shenzhen HCB, Green Building, 2021, http://zjj.sz.gov.cn/xxgk/ztzl/jzjn/

[13] Jin B, 1998, A Political Science Examination of Selected Problems of Bureaucracy. Journal of the Institute of International Relations, 3: 46.

[14] Feng ZF, 2007, The Definition of Movement-Based Governance in China and Its Characteristics. Journal of the Party School of the CPC Yinchuan Municipal Committee 9, 2: 29-32.

[15] Mu XQ, 2017, Local Creation. Fuyukiya Press.

[16] Su CM, 2017, The Strategic Significance and Realistic Challenges of Building the Guangdong-Hong Kong-Macao Greater Bay Area City Cluster. Guangdong Social Science, 4: 5-14. 